Case Report

J Exp Clin Med

2021; 38(2): 208-210

doi: $10.52142 /$ omujecm.38.2.28

\title{
A case of Takayasu's arteritis presented with fever of unknown origin: Diagnostic value of 18f-FDG PET/CT imaging
}

\author{
Sibel Uçak SEMIRGIN ${ }^{1}$ (i), Oktay YAPICI ${ }^{1}$ (i) \\ ${ }^{1}$ Department of Nuclear Medicine, Faculty of Medicine, Ondokuz Mayıs University, Samsun, Turkey
}

\begin{abstract}
Takayasu's arteritis is a chronic vasculitis of the large vessels and has a rare initial presentation of fever of unknown origin (FUO), renders the condition difficult to diagnose. Fluorodeoxyglucose (FDG) positron-emission tomography-computed tomography (PET-CT) can assist in the early diagnosis of Takayasu's Arteritis patients with FUO and can improve the prognosis of such patients. In this case report, we describe a 27 -yearold female presented with one-month history of FUO, showing heterogeneous increased FDG accumulation along the walls of ascending and arch of aorta, left subclavian artery and right brachiocephalic truncus at PET-CT imaging
\end{abstract}

Keywords: FDG PET-CT, Fever of unknown origin, FUO, Takayasu arteritis, vasculitis

\section{Introduction}

Takayasu's arteritis (TA) is chronic vasculitis involving the large vessels particularly the aorta and its major branches (Turlakow et al., 2001). It usually occurs in women under 40 years of age and more common in Asia. Early diagnosis is very essential in patient's prognosis; late diagnosis and inappropriate therapy cause poor prognosis. Imaging modalities take very important part in the diagnosis because there are no specific clinical or laboratory findings and also histopathological examination is not available. Conventional angiography, computerized tomography (CT) or magnetic resonance (MR) angiography are available methods in diagnosis (Seyahi, 2017). 18F-FDG PET-CT is a relatively new imaging method and demonstrates vascular inflammation before structural changes (Chrapko et al., 2016). We reported a patient of TA detected on 18F-FDG PET-CT, with nonspecific symptoms of FUO.

\section{Case Report}

A 27-year-old female presented with about one-month history of FUO ( $\left.\max 38.1^{\circ} \mathrm{C}\right)$, arthralgias in hands, sweating particularly at night, weight loss, fatigue and irregular menstruation. A known chronic illness or medication and contributory family history was not reported. On physical examination of the patient, heart rate was 84 beats/minute and cardiac systolic ejection murmur was heard under the sternum. Body temperature was $37.1^{\circ} \mathrm{C}$. Lymphadenopathy or hepatosplenomegaly was not detected. The notable abnormal laboratory findings were as follows: Erythrocyte sedimentation rate $105 \mathrm{~mm} / \mathrm{h}(\mathrm{N}: 0-20 \mathrm{~mm} / \mathrm{h}), \mathrm{Hb} 10.4 \mathrm{~g} / \mathrm{dL}(\mathrm{N}: 12-15 \mathrm{~g} / \mathrm{dL})$, Fe level $27.3 \mu \mathrm{g} / \mathrm{dL}$ (N:37-145 $\mu \mathrm{g} / \mathrm{dL}$ ), C-reactive protein 74.5 $\mathrm{mg} / \mathrm{L}(\mathrm{N}: 0-3,5 \mathrm{mg} / \mathrm{L}), \operatorname{IgG} 22.2 \mathrm{~g} / \mathrm{L}(\mathrm{N}: 5,5-17 \mathrm{~g} / \mathrm{L}), \operatorname{IgA} 6.17$ $\mathrm{g} / \mathrm{L}(\mathrm{N}: 0,6-3,3 \mathrm{~g} / \mathrm{L})$. There were no other abnormal laboratory findings including markers for neoplastic and infectious diseases. 18F-FDG PET-CT was performed to the patient with a presumptive diagnosis of lymphoma with these findings. After 60 minutes of intravenous injection of $370 \mathrm{MBq} 18 \mathrm{~F}-$ FDG, a whole-body image was obtained for axial, coronal and sagittal images. Heterogeneous increased FDG accumulations were observed along the wall of ascending aorta and aortic arch (SUVmax: 2.61), left subclavian artery (SUVmax: 2.59) and right brachiocephalic truncus (SUVmax: 2.63) (Fig. 1). Significant hypermetabolic focus was not observed suggesting malignant lymphoproliferative disease. Further neck and thorax CT images with iodinated contrast enhancement demonstrated diffuse wall thickening in the bilateral commoninternal-external carotid arteries, subclavian arteries, ascending and descending aorta and right brachiocephalic 
trunk. Moderately luminal narrowing (about 40\%) in the descending aorta (Fig. 2) and severe narrowing in the right brachiocephalic artery and left subclavian artery was detected. All clinical, laboratory and imaging findings were compatible with the final diagnosis of Takayasu Arteritis.
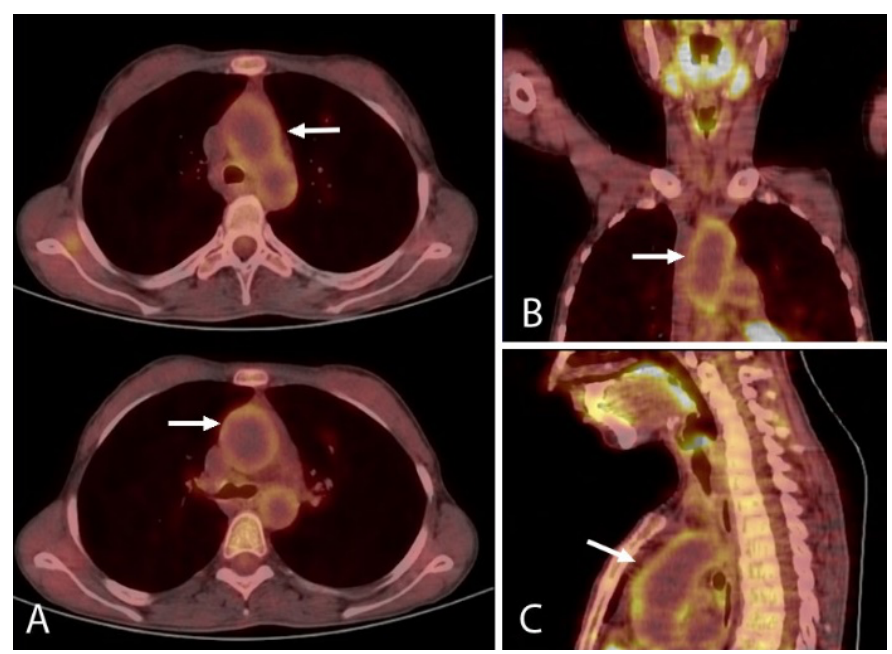

Fig. 1. Axial (A), coronal (B) and sagittal (C) fusion images of 18FFDG PET-CT showed increased radiotracer accumulation along the wall of ascending and arch of aorta

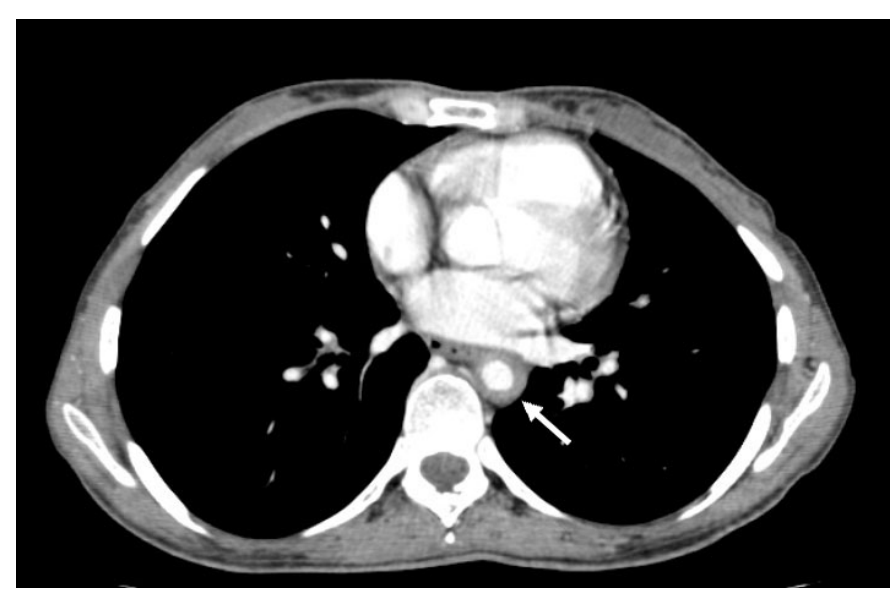

Fig. 2. Thorax CT axial images with iodinated contrast enhancement demonstrated diffuse wall thickening and about 40\% luminal narrowing in the descending aorta

\section{Discussion}

Takayasu's arteritis is a type of large vessel vasculitis and causes inflammation and stenosis mainly in the aorta and its main branches. Acute and chronic phases of the disease were described. In the acute phase, patients generally have nonspecific symptoms such as fatigue, weight loss and FUO associated with vascular inflammation and this causes delayed diagnosis of patients (Pelletier-Galarneau et al., 2019). 18FFDG, a glucose analog, accumulates both in the malign and inflammatory lesions. Several studies demonstrated the value of 18F-FDG PET/CT imaging in the diagnosis and therapy response of large vessel vasculitis (Webb et al., 2004; Arnaud et al., 2009). 18F-FDG accumulations in the wall of aorta and its main branches, may lead to a diagnosis of large vessel vasculitis in patients with inconclusive symptoms (Belhocine et al. 2003; Schreiber et al., 2009). The main feature of this imaging technic is that it has a place in early diagnosis of the disease. Many other imaging modalities including CT or MRI angiography show the morphological changes of the inflammation in chronic phase, whereas 18F-FDG PET/ CT demonstrates inflammatory vascular disease before morphological changes (Hellmich et al., 2009; Vaidyanathan et al., 2015). Kobayashi et al. reported that 18F-FDG accumulation could be intense or weak in active disease, whereas in patients with inactive disease no significant accumulation was observed (Kobayashi et al.,2005). In a study, 18F-FDG PET/CT had a sensitivity of $92 \%$, specificity of $100 \%$, negative predictive value of $85 \%$ and positive predictive value of $100 \%$ in the assessment of active phase of TA (Webb et al., 2004). 18F-FDG PET/CT imaging can be used as a follow-up tool of TA patients. It is the advantage of PET/CT imaging whether increased $18 \mathrm{~F}-\mathrm{FDG}$ uptake in large arteries is a predictor for the development of either clinical relapses or disease progression in TA patients thought to be in remission at follow up (Dejaco et al., 2018). However, it is necessary to be careful in the evaluation of PET/CT findings especially after graft surgery. An observational study evaluated periprosthetic uptake of 18F-FDG in 26 TA patients undergoing graft surgery revealed increased uptake irrespective of disease activity at a median 24 months of follow-up after baseline. Repeated MRI showed a new arterial lesion in a native artery in only one patient, whereas no graft complications were observed despite the persistence of high $18 \mathrm{~F}-\mathrm{FDG}$ periprosthetic scores (Youngstein et al., 2017).

In conclusion, in patients with non-specific inflammatory symptoms including FUO, Takayasu Arteritis should be considered in differential diagnosis. As metabolically pathologies precede morphological changes, 18F-FDG $\mathrm{PET} / \mathrm{CT}$ could be used as a first line imaging modality in those patients.

\section{References}

1. Arnaud, L., Haroche, J., Malek, Z., Archambaud, F., Gambotti, L., Grimon, G., Kas, A., Costedoat-Chalumeau, N., Cacoub, P., Toledano, D., Cluzel, P., Piette, J.C., Amoura, Z. 2009. Ffluorodeoxyglucose positron emission tomography scanning a reliable way to assess disease activity in Takayasu arteritis? Arthritis. Rheum. 60,1193-1200.

2. Belhocine, T., Blockmans, D., Hustinx, R., Vandevivere, J., Mortelmans, L., 2003. Imaging of large vessel vasculitis with 18FDG PET: illusion or reality? A critical review of the literature data. Eur. J. Nucl. Med. Mol. Imaging. 30(9),1305-1313.

3. Chrapko, BE., Chrapko, M., Nocun, A., Stefaniak, B., Zubilewicz, T., Drop, A., 2016. Role of 18F-FDG PET/CT in the diagnosis of inflammatory and infectious vascular disease. Nucl. Med. Rev. Cent. East. Eur. 19, 28-36.

4. Dejaco, C., Ramiro, S., Duftner, C., Besson, FL., Bley, TA., Blockmans, D., Brouwer, E., Cimmino, MA., Clark, E., Dasgupta, B., Diamantopoulos, AP., Direskeneli, H., Iagnocco, A., Klink, T., Neill, L., Ponte, C., Salvarani, C., Slart, RHJA., Whitlock, M., Schmidt, WA. 2018. EULAR recommendations for the use of imaging in large vessel vasculitis in clinical practice. Ann. Rheum. Dis. 77, 636-643.

5. Hellmich, B., Agueda, A., Monti, S., Buttgereit, F., Boysson, H., Brouwer, E., Cassie, R., Cid, M.C., Dasgupta, B., Dejaco, C., 
Hatemi, G., Hollinger, N., Mahr, A., Mollan, S.P., Mukhtyar, C., Ponte, C., Salvarani, C., Sivakumar, R., Tian, X., Tomasson, G., Turesson, C., Schmidt, W., Villiger, P.M., Watts, R., Young, C., Luqmani, R.A. 2009. EULAR recommendations for the management of large vessel vasculitis. Ann. Rheum. Dis. 68, 318323.

6. Kobayashi, Y., Ishii, K., Oda, K., Nariai, T., Tanaka, Y., Ishiwata, K., Numano, F. 2005. Aortic wall inflammation due to Takayasu arteritis imaged with 18 F-FDG PET coregistered with enhanced CT. J. Nucl. Med. 46, 917-922.

7. Pelletier-Galarneau, M., Ruddy, T.D. 2019. PET/CT for Diagnosis and Management of Large-Vessel Vasculitis. Curr. Cardiol. Rep. 21(5), 34 .

8. Schreiber, B.E., Tam, H.H.C., Carvalho, C., Wong, W.L., Russell, A.I., Higgens, C.S. 2009. F-18 PET-CT showing large vessel vasculitis in a patient with high inflammatory markers and no localizing symptoms. Clin. Nucl. Med. 34 (11),785-787.

9. Seyahi, E. 2017. Takayasu arteritis: an update. Curr. Opin. Rheumatol. 29 (1), 51-56.
10. Turlakow, A., Yeung, HW., Pui, J., Macapinlac, H., Liebovitz, E., Rusch, V., Goy, A., Larson, S.M. 2001. Fluodeoxyglucose positron emission tomography in the diagnosis of giant cell arteritis. Arch. Intern. Med. 161,1003-1007.

11. Webb, M., Chambers, A., AL-Nahhas, A., Mason, J.C., Maudlin, L., Rahman, L., Frank, J. 2004. The role of 18F-FDG PET in characterising disease activity in Takayasu arteritis. Eur. J. Nucl. Med. Mol. Imaging. 31,627-634.

12. Vaidyanathan, S., Patel, C.N., Scarsbrook, A.F., Chowdhury, F.U. 2015. FDG PET/CT in infection and inflammation-current and emerging clinical applications. Clin. Radiol. 70,787-800.

13. Youngstein, T., Tombetti, E., Mukherjee, J., Barwick, TD., AlNahhas, A., Humphreys, E., Nash, J., Andrews, J., Incerti, E., Tombolini, E., Salerno, A., Sartorelli, S., Ramirez, GA., Papa, M., Sabbadini, MG., Gianolli, L., De Cobelli, F., Fallanca, F., Baldissera, E., Manfredi, AA., Picchio, M., Mason, JC. 2017. FDG Uptake by Prosthetic Arterial Grafts in Large Vessel Vasculitis Is Not Specific for Active Disease. JACC. Cardiovasc. Imaging. $10,1042-1052$. 